\title{
Radiological protection and assessment of genetic risk
}

\author{
A. G. SEARLE \\ From the MRC Radiobiology Unit, Harwell, Oxon
}

Over the past decade there has been steadily increasing pressure from interested groups of people to quantify the genetic and somatic risks of ionising radiation. The assessment of genetic risk is usually made from data obtained from controlled experiments onanimals, especially mice, often using the concept of the 'doubling dose'. This is the radiation dose which doubles the natural mutation frequency. This value is then applied directly to data on the frequencies of various hereditary diseases in man. The assumption that doubling doses determined for mice can be applied across the whole range of human genetic disease is not firm and requires further validation. However, the use of a single doubling dose for several mutational endpoints does have support as shown in the Figure and the Table. A value of 30 rad might be appropriate for acute exposures and $100 \mathrm{rad}$ for chronic irradiation.

To use the doubling dose concept we need to achieve a clear-cut division of the whole gamut of human hereditary disease into a small number of operationally distinct categories. Where chromosomal changes are concerned it is necessary to distinguish between aneuploidies and structural changes, while for gene mutations and small deficiencies it is not only necessary to distinguish between deleterious dominant and sex-linked conditions and recessives, but also to consider separately those conditions which

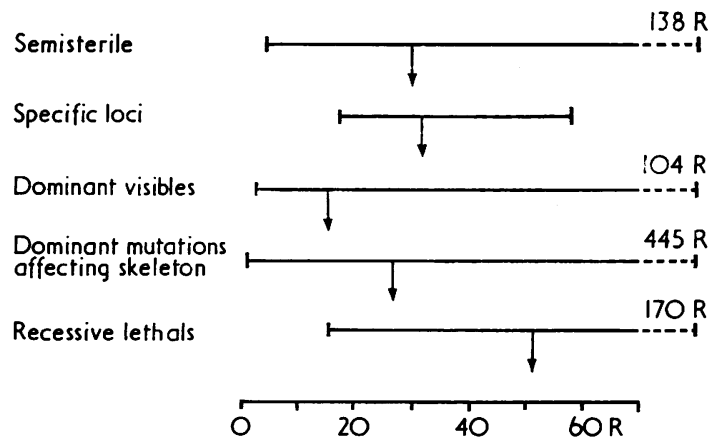

Fig. Comparison of the ranges of acute $X$-ray exposures necessary to induce the same rate of mutations as occur spontaneously per gamete for various groups of mutations in male mice (Lüning and Searle, 1971).

Table Estimates of doubling dose after protracted exposures of mice (Searle and Oftedai, 1975; see also Sankaranarayanan, 1976).

\begin{tabular}{|c|c|c|c|c|}
\hline & $\begin{array}{l}\text { Mutational } \\
\text { event }\end{array}$ & $\begin{array}{l}\text { Type of } \\
\text { radiation }\end{array}$ & $\begin{array}{l}\text { Dose-rate } \\
\text { (rad-min) }\end{array}$ & $\begin{array}{l}\text { Doubling dose } \\
\text { (rad) }\end{array}$ \\
\hline Female & $\begin{array}{l}\text { Specific locus } \\
\text { Dominant } \\
\text { Translocations } \\
\text { Translocations } \\
\text { Specific locus }\end{array}$ & $\begin{array}{l}\gamma \text {-rays } \\
\gamma \text {-rays } \\
\gamma \text {-rays } \\
X \text {-rays } \\
\gamma \text {-rays }\end{array}$ & $\begin{array}{l}0.001-0.009 \\
0.001-0.008 \\
0.02-0.004 \\
0.09 \\
0.003-0.009\end{array}$ & $\begin{array}{r}125 \\
90 \\
210 \\
40 \\
100\end{array}$ \\
\hline
\end{tabular}

have some genetic component but in which the mode of inheritance is irregular and may be multifactorial.

Next, it is necessary to know the normal frequency of members of each category in the population, and for some of these categories there has been quite a wide divergence of estimates in the past. It is also very important to gain some idea of the extent to which these frequencies are maintained by mutation rather than by heterozygous advantage. If not maintained by mutation then their frequency would not be increased by the injection of new mutations into the gene-pool of the population. For some categories, like that of the aneuploidies, especially trisomies, the answer is simple: their frequency is entirely maintained by mutation in the form of non-disjunction (apart perhaps from some XYY's), but with some other categories there is more doubt.

For the radiation protection of workers the most important consideration might be the genetic damage expressed in children and grandchildren rather than the summation over all future generations, which is perhaps more relevant for the assessment of risk in a population. It should be remembered here that people with very disabling conditions may nevertheless pass them on if they tend to act late in life after the age of reproduction. There are also those conditions, like translocations, which are harmless in themselves but which generate unbalanced conditions which may have very deleterious effects.

Lastly, an estimate is required of the average severity of the effect of various hereditary conditions in different categories because it is this rather imprecise concept of 'severity' which can perhaps form 
the bridge between indices of somatic and genetic damage which allows them to be combined into one overall total. However, it should be remembered that the assessment of severity must also involve the time of action. A chromosome aberration which is so severe in its action that it kills at around the time of embryonic implantation is much less traumatic than one killing soon after birth.

These then are the types of human hereditary information we need for the better assessment of genetic risks. It is perhaps worth remembering that what we learn today will be of importance for the assessment not only of radiation risks but of those for any environmental mutagen, and of course will also be a significant contribution to our general knowledge $\Phi$ of human hereditary disease.

\section{References}

Lüning, K. G., and Searle, A. G. (1971). Estimates of the genetic risks from ionising irradiation. Mutation Research, $\overline{\bar{O}}$ 12, 291-304.

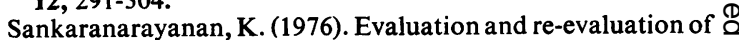
genetic radiation hazards in man. III. Other relevant data and risk assessment. Mutation Research, 35, 387-414.

Searle, A. G., and Oftedal, P. (1975). Per generation doubling $\overrightarrow{0}$ dose estimates. Unpublished report to committee I of the International Commission on Radiological Protection.

Requests for reprints to Dr A. G. Searle, MRC Radiobiology Unit, Harwell, Oxon. OX11 ORD. 